\title{
Potential of Fusarium wilt-inducing chlamydospores, in vitro behaviour in root exudates and physiology of tomato in biochar and compost amended soil
}

\author{
Adnan Akhter • Karin Hage-Ahmed • Gerhard Soja • \\ Siegrid Steinkellner
}

Received: 2 February 2016 / Accepted: 6 June 2016/Published online: 18 June 2016

(C) The Author(s) 2016. This article is published with open access at Springerlink.com

\begin{abstract}
Background and aims Biochars are recognised for their ability to improve soil functions and to stimulate plant defense mechanisms. We evaluated the response of $\mathrm{Fu}$ sarium oxysporum $\mathrm{f}$. sp. lycopersici chlamydospores to tomato plants grown in biochar and compost amended soil to get a deeper insight into the tomato-Fusarium pathosystem.

Methods Wood chips and green waste biochar in combination with compost ('WCB $\mathrm{W}_{\text {comp }}$ and $\mathrm{GWB}_{\text {comp }}$ ' respectively) were studied for their ability to suppress the Fusarium chlamydospores infectivity. Plant growth parameters and in vitro effects on chlamydospores were determined.

Results The ' $\mathrm{GWB}_{\text {comp' }}$ 'soil amendment stimulated plants growth and gaseous exchange rates and had a suppressive effect on the chlamydospore infectivity in comparison with the ' $\mathrm{WCB}_{\text {comp }}$ ' treatment and the treatment containing compost only. The germination rate of
\end{abstract}

Responsible Editor: Jesus Mercado-Blanco.

Electronic supplementary material The online version of this article (doi:10.1007/s11104-016-2948-4) contains supplementary material, which is available to authorized users.

A. Akhter $\cdot$ K. Hage-Ahmed $\cdot$ S. Steinkellner $(\bowtie)$

Department of Crop Sciences, Division of Plant Protection, University of Natural Resources and Life Sciences Vienna, Konrad Lorenz Strasse 24, 3430 Tulln, Austria e-mail: siegrid.steinkellner@boku.ac.at

G. Soja

Department of Health \& Environment, Austrian Institute of Technology, Konrad Lorenz Strasse 24, 3430 Tulln, Austria chlamydospores was unaffected by the source of root exudates, whereas the mycelial growth was significantly higher in root exudates from chlamydospore inoculated plants grown in ' $\mathrm{WCB}_{\text {comp' }}$ ' amended soil unlike to 'GWB $\mathrm{B}_{\text {comp' }}$ ' amended soil.

Conclusion Overall, our findings indicate that both biochars had a variable effect on chlamydospores. We conclude that soil amendment with garden waste biochar and compost exhibit a great potential in suppressing Fusarium chlamydospore infectivity and alleviating pathogen-induced physiological stress in tomato plants.

Keywords Soil amendments · Solanum lycopersicum . Fusarium oxysporum · Germination assay · Fungal growth

\section{Introduction}

Plant pathogenic Fusarium species are remarkably diverse with a broad host range including economic important crops such as tomato, cotton and banana (Smith 2007). According to a recent survey, the scientific community ranked Fusarium oxysporum fifth most important pathogen among the list of top ten plant pathogens (Dean et al. 2012). Fusarium wilt of tomato (Solanum lycopersicum L.) caused by Fusarium oxysporum f. sp. lycopersici (Sacc.) W.C. Snyder and H.N. Hansen, a soil-inhabitant fungus was first described by Massee (1895) in England. This wilt-inducing fungus is a major devastating factor in tomato cultivation worldwide (McGovern 2015). Tomato is ranked second amongst 
the economic important vegetable crops worldwide, with an annual production of 164 million tonnes from 4.73 million hectares of area under cultivation in 2013 (FAOSTAT 2015).

The tomato pathogen F. oxysporum f. sp. lycopersici $(\mathrm{Fol})$ induces blockage of the xylem vessels and, thus, interferes mainly with the water transport causing wilting, yellowing of older leaves, stunted growth and even plant death (Beckman 1987). Depending on the host availability and prevailing environmental conditions, F. oxysporum can produce three types of asexual spores, (I) microconidia (II) macroconidia and (III) chlamydospores, whereas the sexual or teleomorphic stage is unknown. F. oxysporum can survive saprophytically in soil and on plant debris in the absence of a host either as mycelium or in all of the spore types. However, in the regions with cooler climates, F. oxysporum overwinters as chlamydospores (Agrios 2005). In the field chlamydospores are the main survival structures of $F$. oxysporum. DeCal et al. (1997) reported that the chlamydospores of Fol cause a more severe disease development in tomato than microconidia do. Chlamydospores were also found to be more infectious on other crop plants. Couteaudier and Alabouvette (1990) reported enhanced disease severity in flax (Linum usitatissimum), when inoculated with $F$. oxysporum f. sp. lini chlamydospores than with microconidia.

As disease incidence and yield losses due to Fusarium induced-wilt are increasing in both open-field and greenhouse production, it is important to develop promising disease management strategies (McGovern 2015). Chemical control of wilt diseases is neither satisfactory nor environment-friendly (Fravel et al. 2003). Furthermore, the emergence of resistance breaking pathogenic strains emphasizes the necessity for alternative disease management strategies (Takken and Rep 2010). One alternative disease management strategy involves the use of soil organic amendments such as compost and biochar (Smith and Collins 2007; Sohi et al. 2010; Ruano-Rosa and Mercado-Blanco 2015). Composts are known to improve the soil health and to suppress various soil-borne diseases caused by fungal pathogens belonging to diverse genera such as Fusarium, Pythium, Rhizoctonia and Phytophthora (Larkin 2015; Mehta et al. 2014). The suppressiveness of compost may be attributed to a beneficial microbial community, an improvement in plant growth and vigour, an increased nutrient availability, the induction of systemic resistance or to the stronger fungistatic abilities of the compost amendments (Bonanomi et al. 2007).

Biochar is a pyrolytic porous solid coproduct of organic waste material such as wood chips, garden waste material and others (Kammann et al. 2015). Biochar application not only improves crop productivity by modifying the soil structure, $\mathrm{pH}$, cation exchange capacity, porosity, water holding capacity and by increasing the nutrient retention and availability but also stimulates the plant defence system through biochar-borne elicitor chemicals (Sohi et al. 2010; Elad et al. 2010). However, in some studies different biochar types (depending on feedstock and pyrolysis temperature) have been reported to negatively affect crop yield, soil properties and beneficial soil microbiota (Mukherjee and Lal 2014). Previously, biochar has been shown to induce resistance in plants against a variety of aerial as well as soil-borne phytopathogenic fungi and bacteria (Graber et al. 2014; Harel et al. 2012). Jaiswal et al. (2014, 2015) demonstrated the dependency of the disease suppressing ability of different biochars on the feedstock and production parameters. Biochar-induced systemic resistance was documented against gray mold (Botrytis cinerea) and powdery mildew (Oidiopsis sicula) on pepper and tomato (Elad et al. 2010). Recently, Jaiswal et al. (2015) reported that the biochar application suppresses damping off (Rhizoctonia solani) on common bean (Phaseolus vulgaris L.) seedlings. A synergistic effect of biochar and compost has been reported to improve soil fertility, plant growth and beneficial microbial activity in the rhizosphere (Agegnehu et al. 2015; Fischer and Glaser 2012). Only recently, it has been shown that tomato plants growth response and Fol development in plants inoculated with microconidia is dependent on the raw material used for the production of biochars (Akhter et al. 2015).

However, previous studies involving soil-borne fungal pathogens did not evaluate the effectiveness of biochar against the fungal resting spores which have the potential to initiate disease epidemics. To date, no study has assessed the infectivity potential of chlamydospores in biochar-amended soils.

In the presence of a suitable host and favourable environmental conditions such as root exudates and nutrients, chlamydospores germinate to infect plants or to produce more chlamydospores (Kommedahl 1966; Smith and Snyder 1972). Root exudates of tomato plants are already known to stimulate $\mathrm{Fol}$ microconidia germination (Steinkellner et al. 2005). Akhter et al. 
(2015) observed an alteration in the pattern of microconidia germination in response to root exudates from tomato plants grown in soil with compost and biochars. However, the information is scarce regarding the Fusarium chlamydospores response to the plant root exudates grown in soil containing biochar and compost. Therefore, it is imperative to study the effect of soil organic amendments such as biochar and compost on the tomato root exudate-chlamydospore interaction to better understand the onset and progression of tomato wilt together with the development of effective disease management strategies.

In our study, tomato plants were grown in different potting media compositions including biochar and compost, infested with chlamydospores to reproduce natural Fusarium infested field conditions. The prime objective of this study was to evaluate the effectiveness of biochar and compost application in suppressing the infectivity of chlamydospores and to analyse the in vitro growth and development of the main Fol inoculum sources, microconidia, chlamydospores and mycelium in the root exudates. To our knowledge, the results presented here for the first time highlight the potential of biochar and compost application as an soil organic amendment in suppressing the infectivity of chlamydospores and wilt development in tomatoes.

\section{Materials and methods}

Fungal inoculum production

In order to produce microconidia, F. oxysporum f. sp. lycopersici (isolate 007; kindly provided by BJ Cornelissen, University of Amsterdam, The Netherlands) was cultivated for two weeks on Czapek Dox (CZD) agar (Duchefa Biochemie, Haarlem, The Netherlands) in dark at $24{ }^{\circ} \mathrm{C}$. In order to harvest the microconidia, the fungal culture plates were flooded with autoclaved, distilled water and gently rubbed with a Drigalski spatula under aseptic conditions. The liquid fraction was filtered through three layers of fleece cloth filters $(150 \mu \mathrm{m})$. The concentration of microconidial suspension was adjusted according to Steinkellner et al. (2008).

Chlamydospores were obtained by slight modification of the method described by Goyal et al. (1973) and Bennett and Davis (2013). Soil broth was prepared by using sterilised soil (Aussaaterde, Gramoflor $\mathrm{GmbH} \&$ Co. KG, Vechta, Germany) and distilled autoclaved water in the ratio of $1: 4(w / v) ; 250 \mathrm{~g}$ of soil in $1000 \mathrm{ml}$ water were placed on an orbital shaker for $1 \mathrm{~h}$ at $90 \mathrm{rpm}$. Afterwards, the suspension was sieved through $1 \mathrm{~mm}$ sieve to remove large soil particles followed by filtering through 8 layers of fleece cloth filters $(150 \mu \mathrm{m})$. Before autoclaving, the soil broth was separated into aliquots of $50 \mathrm{ml}$ and glucose was added to each aliquot at a concentration of $500 \mu \mathrm{g} / \mathrm{ml}$. A second autoclaving was done on the following day and the remaining sediments in the broth were allowed to settle down for 3 to $4 \mathrm{~h}$, and then $50 \mathrm{ml}$ of soil broth was decanted into sterilised $125 \mathrm{ml}$ flasks. Aliquots of $50 \mathrm{ml}$ of soil broth were inoculated with $300 \mu \mathrm{l}$ of spore suspension $\left(1 \times 10^{7}\right.$ microconidia $/ \mathrm{ml}$ ) and placed near a window under natural light conditions for 7 days at $24{ }^{\circ} \mathrm{C}$ without shaking. Afterwards the contents of the flasks were homogenized with a blender and chlamydospores were quantified with a haemocytometer (Bennett and Davis 2013).

Soil preparation and experimental setup

The substrate used for this experiment sterilized in an autoclave at $121^{\circ} \mathrm{C}$ for $20 \mathrm{~min}$, comprised a mixture of sand (Quarzsand 0-3 mm, Quarzwerke Österreich $\mathrm{GmbH}$, Melk, Austria), leca (Liapor fit Blähton 1$4 \mathrm{~mm}$, Lias Österreich $\mathrm{GmbH}$, Fehring, Austria) and soil (Aussaaterde, Gramoflor GmbH \& Co. KG, Vechta, Germany), in the ratio of 1:1:1 (v/v/v). This substrate was used as an un-amended soil (US) and in combination with compost (Comp) at $20 \%$ and/or biochar at $3 \%$ $(v / v)$. Two types of biochars, namely wood chips biochar (WCB) and green waste biochar (GWB), made from beech wood chips and garden waste residues, respectively, at a pyrolysis temperature of $500{ }^{\circ} \mathrm{C}$ were used in this study. GWB has a comparatively higher $\mathrm{pH}$, higher ash contents and cation exchange capacity. GWB was sieved with a $2 \mathrm{~mm}$ sieve before mixing with potting medium. The compost of quality $\mathrm{A}+$ according to the Austrian compost regulation (BGBl. II Nr. 929/ 2001) was obtained from the municipal compost works in Klosterneuburg, Austria. The compost had a high percentage $(22.7 \%)$ of degradable organic matter contents with a $\mathrm{C} / \mathrm{N}$ ratio of 10 . The detailed characteristics of compost and biochars are available from previous publications of Akhter et al. (2015). Table 1 summarizes the basic properties of the potting-mixture.

For practical applications biochars are usually recommended to be used in combination with compost or with other additional source of fertilization because of 
Table 1 Basic properties of soil, compost, wood chip biochar and green waste biochar

\begin{tabular}{lllll}
\hline Substrate & Organic carbon $(\%)$ & $\mathrm{pH}$ & Electrical conductivity $(\mathrm{mS} / \mathrm{cm})$ & Density $(\mathrm{kg} / \mathrm{L})$ \\
\hline Soil & - & $5.6^{\mathrm{a}}$ & 0.23 & 0.96 \\
Compost & 27.00 & $7.10^{\mathrm{a}}$ & 1.40 & 0.77 \\
Wood chips biochar & 80.30 & $8.78^{\mathrm{b}}$ & 0.54 & 0.36 \\
Green waste biochar & 79.78 & $9.03^{\mathrm{b}}$ & 1.67 & 0.34 \\
\hline
\end{tabular}

- Not specified

${ }^{\mathrm{a}} \mathrm{pH}$ was measured in $\mathrm{CaCl}_{2}$

${ }^{\mathrm{b}} \mathrm{pH}$ was measured in de-ionized water

potential negative effects associated with soil amendment with biochar only (Kammann et al. 2015). The experimental setup comprised the following treatments: (i) Comp (ii) WCB with compost ( $\mathrm{WCB}_{\text {comp }}$ ) (iii) GWB with compost ( $\mathrm{GWB}_{\text {comp }}$ ), and (iv) US. Treatments were either inoculated with chlamydospores $(+\mathrm{Chl})$ or remained pathogen free $(-\mathrm{Chl})$. The experiment was conducted with five replicates in each treatment and each replicate represented a pot with one tomato plant. All the experiments were repeated thrice.

Chlamydospores were mixed with the soil to obtain the final concentration of 5000 chlamydospores/g of dry soil of the potting mix (Rush and Kraft 1986). Soil samples were taken to quantify the fungal inoculum density in the potting mix, both at the beginning and end of the experiment according to Steinkellner and Langer (2004). Air dried soil subsamples of $50 \mathrm{~g}$ each were mixed thoroughly with $100 \mathrm{ml}$ of water agar $(0.15 \%)$ and further diluted by taking $1 \mathrm{ml}$ of suspension in a $9 \mathrm{ml}$ of water agar $(0.15 \%)$. The serial dilutions were made to ten-fold thrice $\left(10^{-3}\right)$ and $1 \mathrm{ml}$ from the dilution was spread uniformly on petri dishes containing Nash-Snyder medium (Nash and Snyder 1962). The petri dishes were incubated for 5-7 days at $22{ }^{\circ} \mathrm{C}$ under UV-light with a photoperiod of 16-h light/8-h dark. Afterwards Fol colonies were counted and represented as colony-forming units per $\mathrm{g}$ of dried soil (CFU/g of dry soil).

Plant material and growth conditions

Tomato cultivar 'Kremser Perle' seeds were surfacesterilised by immersing them in the disinfecting solution [50 \% household bleach ('Dan Clorix', $3.8 \% \mathrm{NaOCl}$ )] for $10 \mathrm{~min}$. Afterwards the seeds were rinsed thoroughly with autoclaved distilled water for three times. The surface-sterilised seeds were cultivated in pots filled with autoclaved perlite (Granuperl S 3-6, Knauf Perlite
$\mathrm{GmbH}$, Vienna, Austria) and incubated in a growth chamber (Rumed, Rubarth Apparate GmbH, Germany) with a 16-h light/8-h dark photoperiod (photosynthetic active radiation $296 \mu \mathrm{mol} / \mathrm{m}^{2} / \mathrm{s}$ ) at $22{ }^{\circ} \mathrm{C}$. The perlite was irrigated with tap water. After 4 weeks, the tomato seedlings were uprooted gently from the perlite and transplanted to separate pots according to the experimental setup. The tomato plants were grown in the greenhouse for 8 weeks, under long day conditions and watered regularly with tap water to sustain optimum moisture conditions for tomato growth (Steinkellner et al. 2005).

Agronomic traits, physiological measurements and extraction of root exudates

Gas exchange measurements [net photosynthetic rate or $\mathrm{CO}_{2}$ assimilation rate at light saturation (Asat)] and stomatal conductance (gs) were measured with a portable photosynthesis system (Li-Cor, Inc. model 6400, Lincoln, Nebraska, USA). The youngest mature leaves of a plant were used for the measurements. All the measurements were made 2 days before harvesting between 10:00 and 14:00 h. After 8 weeks, the data regarding tomato plant phenological growth stage was recorded and plants were harvested by washing the roots with tap water. From each treatment 5 plants were pooled together and roots were dipped for $6 \mathrm{~h}$ in acetate buffer $(25 \mathrm{mM}, \mathrm{pH}=5.5)$ for the extraction of root exudates. The sterile filters $(0.22 \mu \mathrm{m}$, Steriflip, Millipore, Bedford, USA) were used for filtration of root exudates (Hage-Ahmed et al. 2013). For further analysis, the root exudates were adjusted to the concentration of $20 \mathrm{ml} / \mathrm{g}$ of root fresh weight with acetate buffer and stored at $-80{ }^{\circ} \mathrm{C}$. After that, the roots were separated from the base of shoot. Measurements were made for root fresh weight, root length, shoot fresh 
weight and shoot height. In order to obtain the dry weights, roots and shoots were placed in an oven at $60{ }^{\circ} \mathrm{C}$ until weight was unchanged.

Disease incidence and severity assessment

The $\mathrm{Fol}$ incidence and severity assessment were made according to Akhter et al. (2015). Briefly, plants were assessed for disease incidence both visually and by incubating a surface-sterilized segment of the shoot base $(0.5 \mathrm{~cm})$ on potato dextrose agar [(PDA), Carl Roth $\mathrm{GmbH}+\mathrm{Co}$. KG, Germany)] plates at $24{ }^{\circ} \mathrm{C}$ in the dark. Disease incidence was calculated for each batch of five plants separately by using the following formula:

Disease incidence $=\frac{\text { Number of infected plants }}{\text { Total number of plants }} \times 100$

In order to assess the disease severity, the length of the xylem vessel with brownish discoloration was estimated. The plants were assigned to a category on a scale of $1-5(\mathrm{c} 1=1-5 \%, \mathrm{c} 2=5-15 \%, \mathrm{c} 3=15-35 \%$, $\mathrm{c} 4=35-67.5 \%$, c5 $=67.5-100 \%$ ) according to the length of xylem vessel discoloration. Disease severity was calculated for a batch of five plants in each treatment by the following formula:

Disease severity

$$
=\frac{5 \mathrm{x}(\mathrm{nc} 1+2 \mathrm{nc} 2+5 \mathrm{nc} 3+10 \mathrm{nc} 4+20 \mathrm{nc} 5)}{\text { number of infected plants }}
$$

In vitro effect of compost and biochar to chlamydospores

The effect of compost and the two types of biochar on the mycelial growth and hyphal development of $\mathrm{Fol}$ was evaluated on PDA plates amended with antibiotics $(10 \mathrm{mg} / \mathrm{l}$ of each Streptomycinsulfat and Chloramphenicol) to prevent bacterial contamination. The compost and biochars were sieved through $100 \mu \mathrm{m}$ sieves before mixing with growth media. The PDA was amended with compost $(20 \%)$ alone and in combination with $\mathrm{WCB} /$ or $\operatorname{GWB}(3 \%, w / v)$ before autoclaving (Jaiswal et al. 2015). The amended PDA was poured into petri dishes (diameter $=9 \mathrm{~cm}$ ). After solidification of the media, sterilised filter paper segments (diameter $=6 \mathrm{~mm}$ ) were placed in the centre of petri dishes. For inoculation with chlamydospores, $5 \mu$ l of the suspension $\left(1 \times 10^{5}\right.$ chlamydospores $/ \mathrm{ml}$ ) was applied directly on the filter paper and the dishes were incubated under dark conditions at $24{ }^{\circ} \mathrm{C}$ for 5 days. At the end of the incubation period, the mycelial growth was determined by measuring the fungal colony diameter $(\mathrm{cm})$. The data were collected from six replicates arranged randomly. The inhibition percentage of the mycelial radial growth in the compost and biochar amended media $\left(\mathrm{A}_{\mathrm{med}}\right)$ and in the un-amended control $\left(\mathrm{UA}_{\text {cont }}\right)$ was measured with the following formula:

$\operatorname{Inhibition}(\%)=\left[\left(U A_{\text {cont }}-A_{\text {med }}\right) / U A_{\text {cont }}\right] \times 100$

In vitro fungal growth assays (microconidia germination assay, chlamydospore germination assay and mycelial development in tomato root exudates)

The fungal growth assays were performed in 96-well plates (NUNCLONTM D Surface, F96 MicroWellTM Plates, NUNCTM Brand Products, Roskilde, Denmark). The root exudates were analysed in triplicates. In order to evaluate the microconidia germination rate, $35 \mu \mathrm{l}$ of a conidial spore suspension $\left(1 \times 10^{7}\right.$ microconida $/ \mathrm{ml}$ ) was added into $175 \mu$ of root exudates into each well of 96-well plate incubated for $20 \mathrm{~h}$ at $24{ }^{\circ} \mathrm{C}$. Likewise, for chlamydospore germination assay, aliquots of $175 \mu \mathrm{l}$ of root exudates were mixed with $35 \mu \mathrm{l}$ of chlamydospore suspension $\left(1 \times 10^{5}\right.$ chlamydospore/ml) and incubated at $24{ }^{\circ} \mathrm{C}$ in dark on a rotary shaker at $200 \mathrm{rpm}$ for $10 \mathrm{~h}$. The microconidia germination rate (\%) was determined by counting 200 spores/ well and chlamydospore germination rate was recorded by counting 100 chlamydospores/well microscopically. The 96-well plates for the mycelial growth assay were prepared as described for the chlamydospore germination assay. The mycelial growth and development was assessed by evaluating the optical density at $600 \mathrm{~nm}$ for a total period of five successive days after regular intervals, with a spectrophotometer (FLUOstar Omega, BMG LABTECH GmbH, Ortenberg, Germany) according to Steinkellner and Mammerler (2007). The CZD broth and acetate buffer served as a positive and negative control, respectively, for all fungal growth assays.

Statistical analysis

A two-way general linear model analysis of variance (ANOVA) was used to compare the significant effects of 
main factors [treatment (different soil substrate compositions) and chlamydospore] and their interaction (treatment $\mathrm{x}$ chlamydospore) on root and shoot dry biomass, root length, shoot height, net photosynthetic rate and stomatal conductance, in vitro mycelial growth, microconidia and chlamydospore germination rate. A one-way ANOVA was performed on disease incidence, disease severity, $\mathrm{CFU}$ of $\mathrm{Fol} / \mathrm{g}$ of dry soil and on in vitro toxicity of compost and biochars since the data from 'Chl' treatments was zero. The data were logtransformed for the CFU of Fol/g of dry soil. All the replicates were analysed together with experimental repeats. Percentage data was transformed before analysis (Jaiswal et al. 2015). Levene's test was used to check the homogeneity of variances. The individual treatment means were compared using Tukey's honestly significant difference (HSD) test, with a significant level at $P \leq 0.05$. All statistical tests were performed using PASW Statistics 18 (Version 18.0.0, IBM, Armonk, NY, USA) software.

\section{Results}

Effect of compost and biochar on disease incidence, severity and chlamydospore survival

Disease incidence and severity was determined 8 weeks after transplanting tomato plants to the chlamydosporesinfested potting media (Table 2). There was no significant difference in disease incidence between compost (Comp $+\mathrm{Chl} ; 60 \%$ ) and wood chips biochar ( $\mathrm{WCB}_{\text {comp }}+\mathrm{Chl} ; 66 \%$ ) amended treatments. However, in the potting media comprising green waste biochar ('GWB ${ }_{\text {comp }}+$ Chl') the disease incidence $(20 \%)$ was significantly reduced. Likewise, we also observed a

Table 2 Effect of different soil substrate compositions comprising compost, compost with wood chips biochar $\left(\mathrm{WCB}_{\text {comp }}\right)$ and green waste biochar $\left(\mathrm{GWB}_{\mathrm{comp}}\right)$ and un-amended soil inoculated with significant $(P<0.001)$ reduction of disease severity in

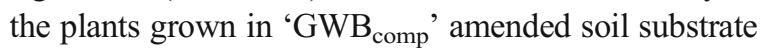
$(5.7 \pm 0.94)$ as compared to the plants grown in 'Comp +

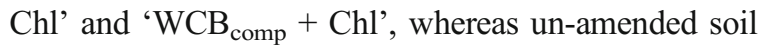
control ('US + Chl') has depicted maximum Fusarium incidence $(100 \%)$ and severity $(87 \pm 5.20)$. The uninfested soil treatments did not show any Fusarium symptoms.

The colony forming units (CFUs) of Fol/g of dry soil decreased significantly in the treatments containing compost alone and compost-biochar mixture in comparison with soil without any organic amendment (US + $\left.\mathrm{Chl} ; 6.78 \times 10^{4}\right)$. Among compost and biochar amended treatments, green waste biochar $\left(\mathrm{GWB}_{\text {comp }}\right)$ comprising soil substrate has shown the lowest $\left(0.30 \times 10^{4}\right) \mathrm{CFU} / \mathrm{g}$ of dry soil, whereas no significant difference in Folchlamydospore survival was recorded in 'Comp' and ' $\mathrm{WCB}_{\text {comp' }}$ amended treatments (Table 2). No Fusarium colony was observed in chlamydospore-free treatments.

\section{Effect of compost and biochar on fungal growth}

The response of Fusarium chlamydospores in PDA media amended with compost alone and in association with biochar (' $\mathrm{WCB}_{\text {comp }}$ ' or ' $\mathrm{GWB}_{\text {comp }}$ ') as well as unamended control ( $\left.\mathrm{UA}_{\text {cont }}\right)$ is summarized in Table 3. There was almost similar radial growth of $\mathrm{Fol}$ in media

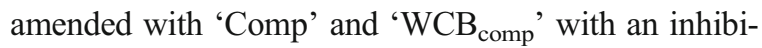
tion of $8.27 \%$ and $12.84 \%$ of mycelium radial growth, respectively. On the other hand, it was observed that the addition of ' $\mathrm{GWB}_{\text {comp }}$ ' in PDA has efficiently suppressed the Fusarium radial growth. There was a significantly higher $(P<0.01)$ inhibition $(31.27 \%)$ of Fusarium radial growth in ' $\mathrm{GWB}_{\text {comp' }}$ ' amended fungal growth media as compared to the un-amended control.

chlamydospores $(+\mathrm{Chl})$, on the disease incidence, disease severity and on colony forming units (CFU) of Fol/g of dry soil, 8 weeks after transplanting

\begin{tabular}{lllll}
\hline Treatments & Comp + Chl & WCB $_{\text {comp }}+$ Chl & GWB $_{\text {comp }}+$ Chl & US + Chl \\
\hline Disease incidence (\%) $^{1}$ & $60.00 \pm 0.00^{\mathrm{b}}$ & $66.67 \pm 11.54^{\mathrm{b}}$ & $20.00 \pm 0.00^{\mathrm{c}}$ & $100 \pm 0.00^{\mathrm{a}}$ \\
Disease severity $^{\mathrm{b}}$ & $14.45 \pm 2.55^{\mathrm{b}}$ & $16.39 \pm 4.27^{\mathrm{b}}$ & $5.67 \pm 0.94^{\mathrm{c}}$ & $87.00 \pm 5.20^{\mathrm{a}}$ \\
CFU/g dry soil $^{2}\left(\times 10^{4}\right)$ & $0.44 \pm 0.12^{\mathrm{b}}$ & $0.47 \pm 0.12^{\mathrm{b}}$ & $0.30 \pm 0.08^{\mathrm{c}}$ & $6.78 \pm 1.24^{\mathrm{a}}$ \\
\hline
\end{tabular}

\footnotetext{
${ }^{1}$ Data are mean values \pm standard deviation followed by different letters in the superscript within each row indicate significant differences according to Tukey's HSD test $(P<0.05)$

${ }^{2}$ Data represent mean values \pm standard deviation followed by different letters in the superscript within each row indicates significant differences according to Tukey's HSD test $(P<0.05)$. For statistical analysis data has been transformed $(\log )$
} 
Table 3 In vitro evaluation of fungal radial growth $(\mathrm{cm})$ and inhibition (\%) to the direct toxicity of compost (Comp) alone and in combination with wood chips and green waste biochar ( $\mathrm{WCB}_{\text {comp }}$ and $\mathrm{GWB}_{\text {comp }}$ respectively) compared to the unamended control ( $\left.\mathrm{UA}_{\text {cont }}\right)$

\begin{tabular}{lll}
\hline Treatments & Radial growth $(\mathrm{cm})$ & Inhibition (\%) \\
\hline $\mathrm{UA}_{\text {cont }}$ & $7.82 \pm 0.25^{\mathrm{a}}$ & \\
$\mathrm{Comp}$ & $7.22 \pm 0.15^{\mathrm{b}}$ & $8.27 \pm 2.32^{\mathrm{b}}$ \\
$\mathrm{WCB}_{\text {comp }}$ & $6.93 \pm 0.17^{\mathrm{b}}$ & $12.84 \pm 2.71^{\mathrm{b}}$ \\
GWB $_{\text {comp }}$ & $5.96 \pm 0.71^{\mathrm{c}}$ & $31.27 \pm 5.52^{\mathrm{a}}$ \\
\hline
\end{tabular}

Data are mean values \pm standard deviation followed by different letters in the superscript within a column denote significant differences according to Tukey's HSD test $(P<0.05)$

Effect of compost, biochar and chlamydospores on plant growth and gas exchange parameters

In the presence of compost, green waste biochar has promoted plant growth both in chlamydospore inoculated $(+\mathrm{Chl})$ and un-inoculated $(-\mathrm{Chl})$ tomato plants (Fig. 1a, b). Among all the treatments, tomato plants grown in ' $\mathrm{GWB}_{\text {comp }}$ ' amended soil substrate had higher root $(0.71 \mathrm{~g})$ and shoot dry biomass $(2.67 \mathrm{~g})$ yield. Moreover, the plants in 'GWB' amended substrate has sustained the disease stress more effectively then 'Comp + Chl, $\mathrm{WCB}_{\mathrm{comp}}+\mathrm{Chl}$ and US + Chl' treatments. There was a substantial decrease in root and shoot dry biomass of ' $+\mathrm{Chl}$ ' plants grown in 'Comp' and ' $\mathrm{WCB}_{\text {comp }}$ ' treatments as compared to their respective un-inoculated counterparts. The maximum Fusarium chlamydospore induced reduction in root dry biomass was recorded in ' $\mathrm{WCB}_{\text {comp }}+\mathrm{Chl}$ ' $(0.36 \mathrm{~g})$ as compared to its respective un-inoculated control ('WCB comp $_{-}-C_{1}$ '; $0.55 \mathrm{~g}$ ). The significant reduction in root dry biomass in all of the inoculated treatments were ranked as (from minimum to maximum reduction) ' $\mathrm{GWB}_{\text {comp }}+\mathrm{Chl} \mathrm{Comp}+\mathrm{Chl} \quad \mathrm{WCB}_{\text {comp }}{ }^{+}$ Chl US+Chl' (Fig. 1a), whereas in case of the shoot dry biomass treatments were ordered as ' $\mathrm{GWB}_{\text {comp }}+\mathrm{Chl}$ Comp $+\mathrm{Chl} \approx \mathrm{WCB}_{\text {comp }}+$ Chl US + Chl' (Fig. 1b).

The chlamydospore inoculated tomato plants grown

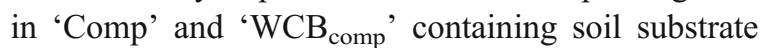
remained shorter in stature $(21.14 \mathrm{~cm}$ and $18.16 \mathrm{~cm}$ respectively), when compared with the plants grown in 'GWB comp + Chl' (31.03 cm) (Fig. 2b). However, we did not observe any significant differences in root length between compost and biochar amended treatments, although there was approximately 2.5 to 3 fold increase in root length as compared to + Chl plants grown in 'US' (Fig. 2a).

Significant effects of main factors [treatment (different soil substrate compositions) and chlamydospore)] and their interactions (treatment $\times$ chlamydospore) are

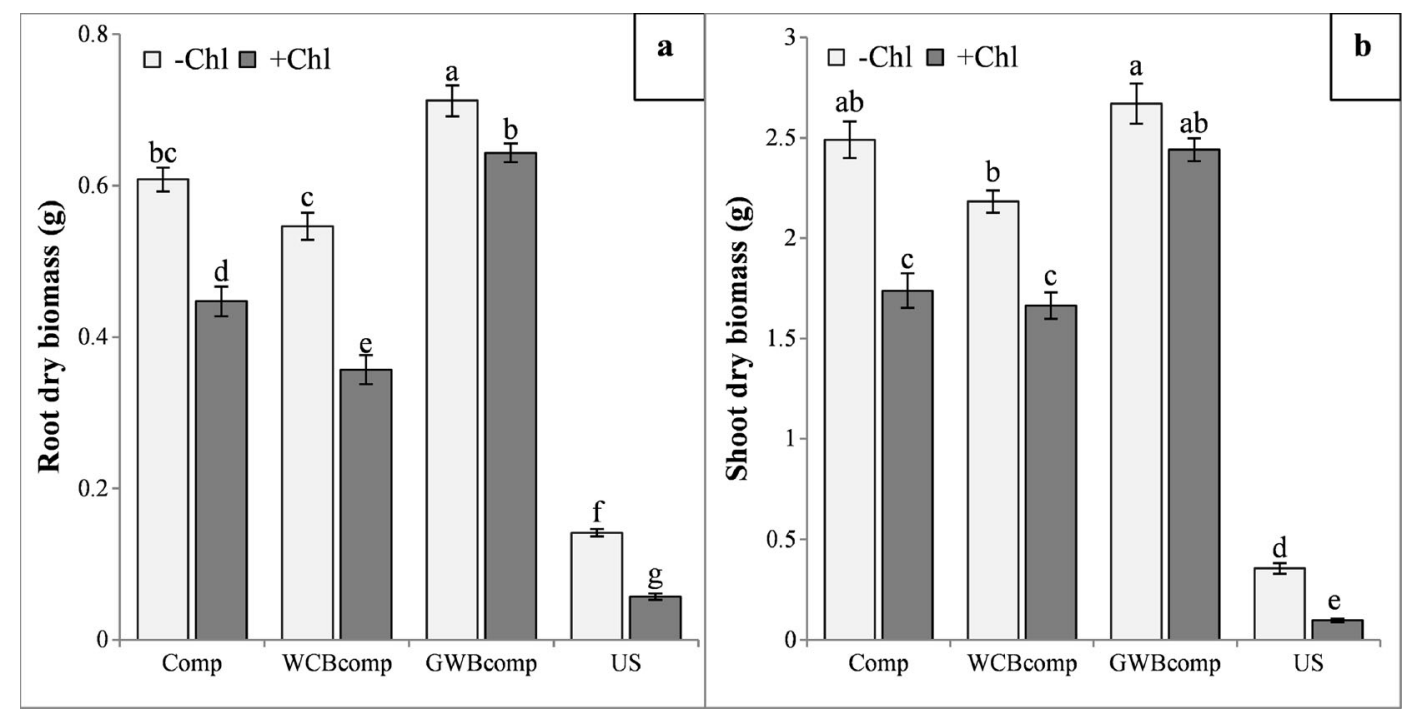

Fig 1 Root (panel a) and shoot dry biomass (panel b) of tomato plants either inoculated with chlamydospores (+Chl; dark bars) or un-inoculated ( $-\mathrm{Chl}$; light bars) grown in different soil substrates comprising compost (Comp), compost and wood chips biochar $\left(\mathrm{WCB}_{\mathrm{comp}}\right)$, compost and green waste biochar $\left(\mathrm{GWB}_{\mathrm{comp}}\right)$ or in un-amended soil (US). Data were collected 8 weeks after transplanting. Data are mean values \pm standard error; different letters above bars denote significant differences according to Tukey's HSD test $(P<0.05)$ 


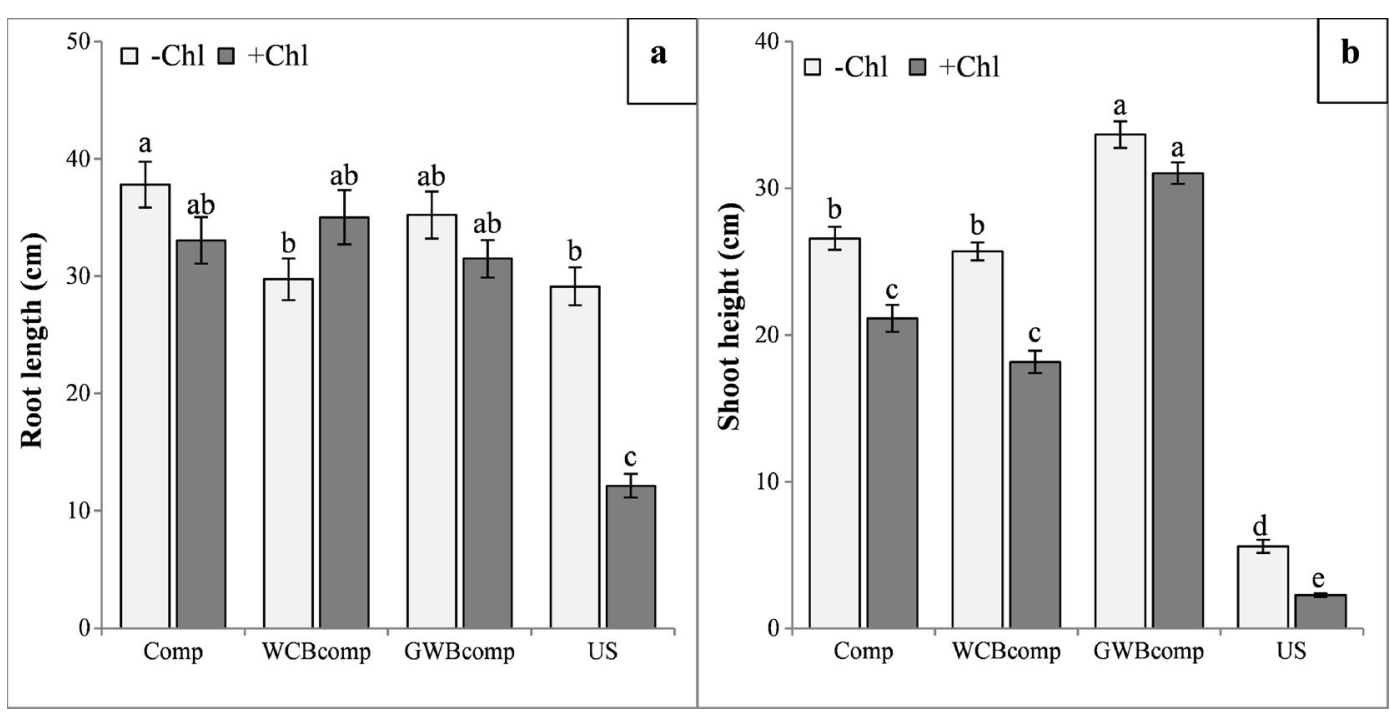

Fig 2 Root length (panel a) and shoot height (panel b) of tomato plants either inoculated with chlamydospores (+Chl; dark bars) or uninoculated ( $-\mathrm{Chl}$; light bars) grown in different soil substrates comprising compost (Comp), compost and wood chips biochar $\left(\mathrm{WCB}_{\mathrm{comp}}\right)$,

summarized in Table 4. Overall, significant interactive effect of main factors treatment and chlamydospore was observed in the tomato plants growth and physiological parameters including root and shoot dry biomass, root length, shoot height and stomatal conductance. compost and green waste biochar $\left(\mathrm{GWB}_{\mathrm{comp}}\right)$ or in un-amended soil (US). Data were collected 8 weeks after transplanting. Data are mean values \pm standard error; different letters above bars denote significant differences according to Tukey's HSD test $(P<0.05)$

However, in case of photosynthetic rate or net- $\mathrm{CO}_{2}$ assimilation rate (Asat) only a significant effect of main factors treatment and chlamydospore was documented.

Amongst the 'Comp' and biochar amended treatments, chlamydospore inoculation significantly reduced

Table 4 Statistical results of the two-way ANOVA presented as $F$ values and level of significance $(P)$ on plant growth and physiological parameters and on in vitro fungal growth and development

\begin{tabular}{llll}
\hline Variables & Main effects & & Interaction effects \\
\cline { 2 - 4 } & Treatment $^{\mathrm{a}}$ & Chlamydospore $^{\mathrm{b}}$ & Treatment $\times$ Chlamydospore \\
\hline Agronomic and physiological parameters & & & \\
Root dry biomass & $92.86^{* *}$ & $84.29^{* *}$ & $6.32^{*}$ \\
Shoot dry biomass & $32.69^{* *}$ & $59.75^{* *}$ & $5.20^{*}$ \\
Root length & $1.28^{\mathrm{NS}}$ & $0.46^{\mathrm{NS}}$ & $4.01^{*}$ \\
Shoot height & $96.67^{* *}$ & $63.70^{* *}$ & $4.72^{*}$ \\
Net photosynthetic rate & $44.14^{* *}$ & $81.38^{* *}$ & $3.07^{\mathrm{NS}}$ \\
Stomatal conductance & $16.49^{* *}$ & $325.54^{* *}$ & $27.77^{* *}$ \\
Fungal growth parameters & & $65.72^{* *}$ & $0.59^{\mathrm{NS}}$ \\
Microconidia germination & $73.45^{* *}$ & $0.00^{\mathrm{NS}}$ & $0.48^{\mathrm{NS}}$ \\
Chlamydospore germination & $0.49^{\mathrm{NS}}$ & $466.57^{* *}$ & $215.30^{* *}$ \\
Mycelial growth assay & $115.79^{* *}$ & &
\end{tabular}

$N S$ not significant

$* P<0.05$

$* * P<0.001$

${ }^{\mathrm{a}}$ Factor treatment represents different soil substrate compositions

${ }^{\mathrm{b}}$ Factor chlamydospore represents inoculated or un-inoculated plants 
net- $\mathrm{CO}_{2}$ assimilation rate in 'Comp $+\mathrm{Chl}$ ' (12.67) and

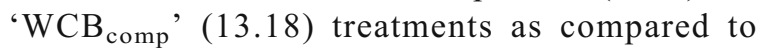
'GWBcomp' (Table 5). In the absence of chlamydospores, the plants grown in 'GWB' amended substrate ('GWB comp ') showed maximum (17.78) rate of photosynthesis and remained in higher ranges among the plants under Fusarium chlamydospore stress ('Comp + GWB + Chl'; 15.67). The differences in stomatal conductance (gs) in the absence of chlamydospores were not significant between the treatments. However, a reduction in 'gs' was observed in the treatment 'Comp + Chl' (0.105) and 'WCB ${ }_{\text {comp }}+\mathrm{Chl}^{\prime}$ ' (0.109), whereas the plants grown in ' $\mathrm{GWB}_{\text {comp }}+\mathrm{Chl}$ ' had maintained higher level (0.117) of 'gs' upon exposure to Fusarium chlamydospore stress (Table 5).

Influence of root exudates on in vitro fungal growth and development of Fusarium oxysporum f. sp. lycopersici spores and mycelium

\section{Microconidia germination in root exudates}

Depending on the composition of potting media and the inoculum source for $\mathrm{Fol}$ inoculation, the microconidia germination rate was between 16 and $63.2 \%$ in the tomato root exudates (Fig. 3). The $\mathrm{pH}$ values of root exudates ranged between 5.82 and 6.00 (data not shown). The main factor treatment and chlamydospore had significant $(P<$ 0.001 ) effects on the microconidia germination (Table 4$)$. The minimum germination rate $(5.5 \%)$ was observed in the acetate buffer (negative control), whereas maximum germination rate $(68.44 \%)$ corresponded to the CZD broth which served as a positive control of the germination assay. Overall, the germination rate was higher in root exudates from chlamydospore inoculated treatments as

Table 5 Net photosynthetic rate and stomatal conductance (gs) of tomato leaves as affected by different soil substrate compositions [compost (Comp), combination of compost with wood chips compared to their respective un-inoculated counterparts, except in case of root exudates of plants from treatment 'US'. The Fol microconidia germination rate was highest in root exudates from plants grown in treatments 'Comp + Chl' (63.22\%) and 'Comp-Chl' (56.39\%). However, the germination rate was reduced in root exudates of plants from biochar amended treatments, with the minimum in 'GWB comp $-\mathrm{Chl}$ ' (42.28\%). No significant differences in germination rate were observed between ' $\mathrm{WCB}_{\text {comp }}+$ Chl' $(53.72 \%)$ and 'GWB ${ }_{\text {comp }}+\mathrm{Chl}^{\prime}(51.05 \%)$ treatments.

II. Chlamydospore germination in root exudates

The experiments to assess the chlamydospore germination rate indicated that the chlamydospores germinated efficiently in the root exudates and reached up to $98 \%$ of germination after $10 \mathrm{~h}$ of incubation period (Fig. 4). The lowest germination rate was recorded in acetate buffer $(17.56 \%)$ and the maximum in root exudates from treatments 'WCB ${ }_{\text {comp }}+$ Chl' $(98.44 \%)$ and 'Comp + Chl' $(98.33 \%)$. We did not observe any significant difference in the chlamydospore germination rate in the root exudates from compost and biochar amended treatments either inoculated or un-inoculated with chlamydospores except in case of the exudates from 'un-amended soil where the germination rate was reduced to $90 \%$ and $92.2 \%$ in '-Chl' and ' + Chl' treatments, respectively, as well as in the CZD broth control (90\%).

III. Mycelial growth and development in root exudates

Mycelial growth and development from chlamydospores was assessed in the root exudates of the different

biochar $\left(\mathrm{WCB}_{\text {comp }}\right) /$ or with green waste biochar $\left(\mathrm{GWB}_{\text {comp }}\right)$ or un-amended soil (US)] either inoculated $(+\mathrm{Chl})$ with wilt-inducing chlamydospores or un-inoculated $(-\mathrm{Chl})$

\begin{tabular}{|c|c|c|c|c|}
\hline \multirow[t]{2}{*}{ Treatments } & \multicolumn{2}{|c|}{ Net photosynthetic rate $\left(\mu \mathrm{mol} \mathrm{CO} \mathrm{CO}^{-2} \mathrm{~s}^{-1}\right)$} & \multicolumn{2}{|c|}{ Stomatal conductance $(\mathrm{gs})\left(\mathrm{mol} \mathrm{H}_{2} \mathrm{O} \mathrm{m}^{-2} \mathrm{~s}^{-1}\right)$} \\
\hline & $-\mathrm{Chl}$ & $+\mathrm{Chl}$ & $-\mathrm{Chl}$ & $+\mathrm{Chl}$ \\
\hline Comp & $15.89 \pm 1.07^{\mathrm{b}}$ & $12.67 \pm 1.36^{\mathrm{c}}$ & $0.124 \pm 0.004^{\mathrm{a}}$ & $0.105 \pm 0.005^{\mathrm{c}}$ \\
\hline $\mathrm{WCB}_{\mathrm{comp}}$ & $14.87 \pm 0.81^{\mathrm{b}}$ & $13.18 \pm 1.46^{\mathrm{c}}$ & $0.127 \pm 0.002^{\mathrm{a}}$ & $0.109 \pm 0.003^{\mathrm{c}}$ \\
\hline $\mathrm{GWB}_{\text {comp }}$ & $17.78 \pm 1.36^{\mathrm{a}}$ & $15.67 \pm 1.21^{\mathrm{b}}$ & $0.123 \pm 0.004^{\mathrm{ab}}$ & $0.117 \pm 0.004^{\mathrm{b}}$ \\
\hline US & $09.23 \pm 0.94^{\mathrm{d}}$ & $04.76 \pm 0.88^{\mathrm{e}}$ & $0.083 \pm 0.001^{\mathrm{d}}$ & $0.042 \pm 0.002^{\mathrm{e}}$ \\
\hline
\end{tabular}

Data are mean values \pm standard deviation followed by different letters in the superscript under the same parameter denote significant differences according to Tukey's HSD test at $P<0.05$ 


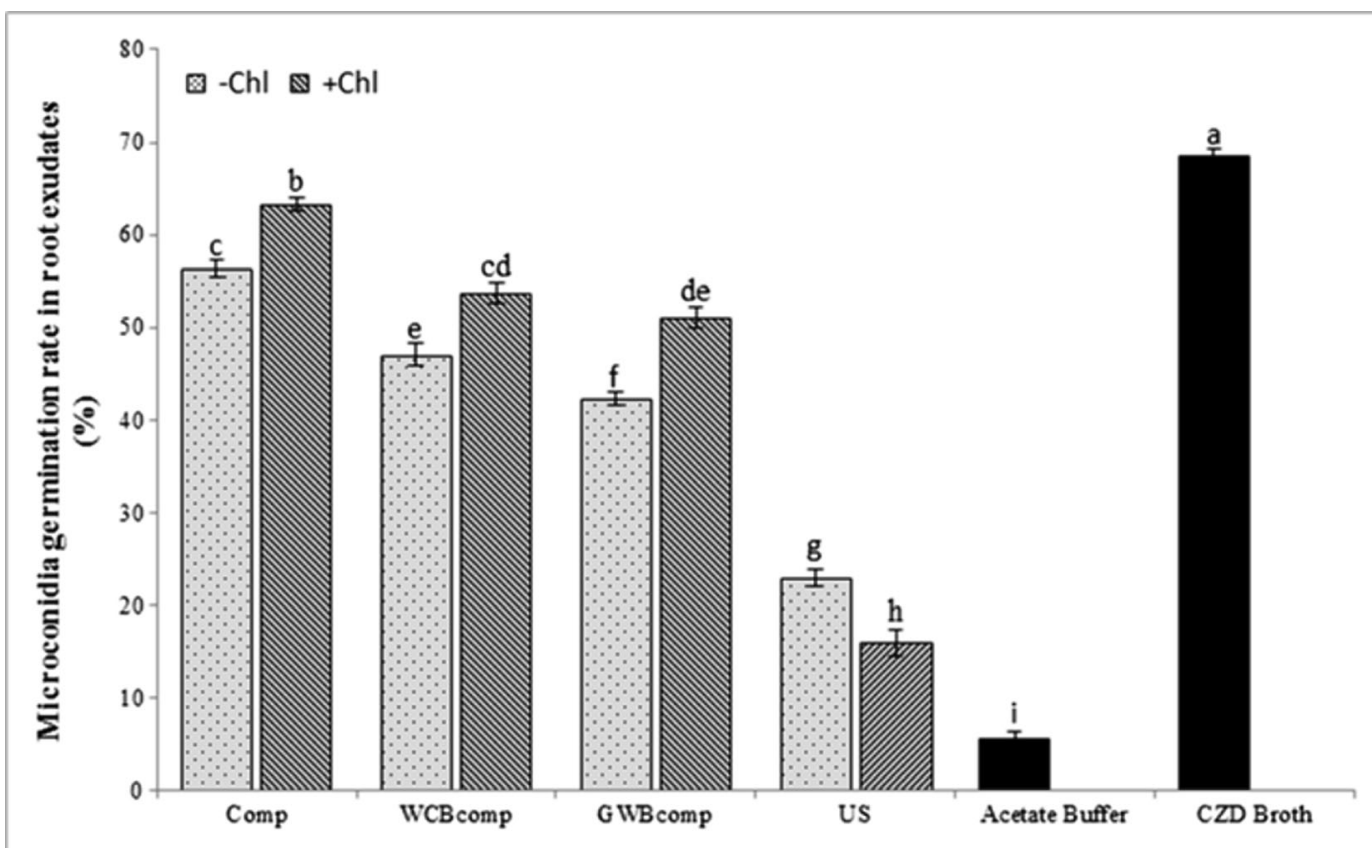

Fig 3 Differences in microconidia germination rate of Fusarium oxysporum f. sp. lycopersici in root exudates from tomato plants either inoculated with chlamydospores $(+\mathrm{Chl})$ or un-inoculated (-Chl) grown in different soil substrates comprising compost (Comp), compost and wood chips biochar $\left(\mathrm{WCB}_{\text {comp }}\right)$, compost and green waste biochar ( $\left.\mathrm{GWB}_{\text {comp }}\right)$ or in un-amended soil (US)

treatments for five consecutive days (Fig. 5). The CZD broth produced maximum optical density $(2.89 \pm 0.04)$, whereas the minimum optical density $(0.148 \pm 0.01)$ was observed in the acetate buffer (Supplementary Table 1). Different soil substrate compositions either inoculated or un-inoculated with chlamydospores had a varying influence on the tomato root exudates which in turn altered the mycelial growth and development from chlamydospores. There was a significant $(P<0.001)$ interaction effect of treatment and chlamydospores on the mycelial growth and development (Table 4). Among the biochar amended treatments in the absence of chlamydospores inoculation

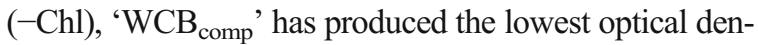
sity $(0.381 \pm 0.01)$, while the maximum $(0.525 \pm 0.01)$ was in root exudates from ' $\mathrm{GWB}_{\text {comp }}$ ' treatment. Contrarily, greatest stimulation of the mycelial growth was observed in ' $\mathrm{WCB}_{\text {comp }}+\mathrm{Chl}$ ' (47.51\%). 'Comp + Chl' and 'US + Chl' increased mycelial growth by 8.8 and $9.1 \%$, respectively. However, there was no significant difference observed in mycelial growth and development in the root exudates of plants grown in ' $\mathrm{GWB}_{\text {comp }}$ ' amended treatment either inoculated or un-inoculated with chlamydospores. after $20 \mathrm{~h}$ at $24^{\circ} \mathrm{C}$. Bars with solid filling represent microconidia germination rate in acetate buffer (negative control) and Czapek dox medium (Positive control; CZD). Data are mean values \pm standard error with different letters above bars that denote significant differences according to Tukey's HSD test $(P<0.05)$

\section{Discussion}

During the recent years, biochar induced plant protection has been demonstrated against several foliar and soil-borne phytopathogenic bacteria and fungi (Graber et al. 2014; Jaiswal et al. 2015). The plant growth response of tomato plants inoculated with $\mathrm{Fol}$ microconidia has been studied well (Akhter et al. 2015). However, as chlamydospores are the main source of inoculum, their effect on root exudation and subsequent disease suppression phenomena is of great interest to the growers as well as to phytopathologists. In our study, we have shown the capability of biochar and compost in the plant growth medium to reduce the infectivity potential of wilt-inducing chlamydospores.

Generally, the disease causing potential of chlamydospores of $\mathrm{Fol}$ is ranked higher than microconidia (DeCal et al. 1997). Silva-Muniz et al. (1991) observed a greater infectivity of $F$. oxysporum f. sp. phaseoli chlamydospores than microconidia either because of the increased ability of germ tubes to penetrate roots or due to the release of a higher amount of toxins harmful to the plants. 


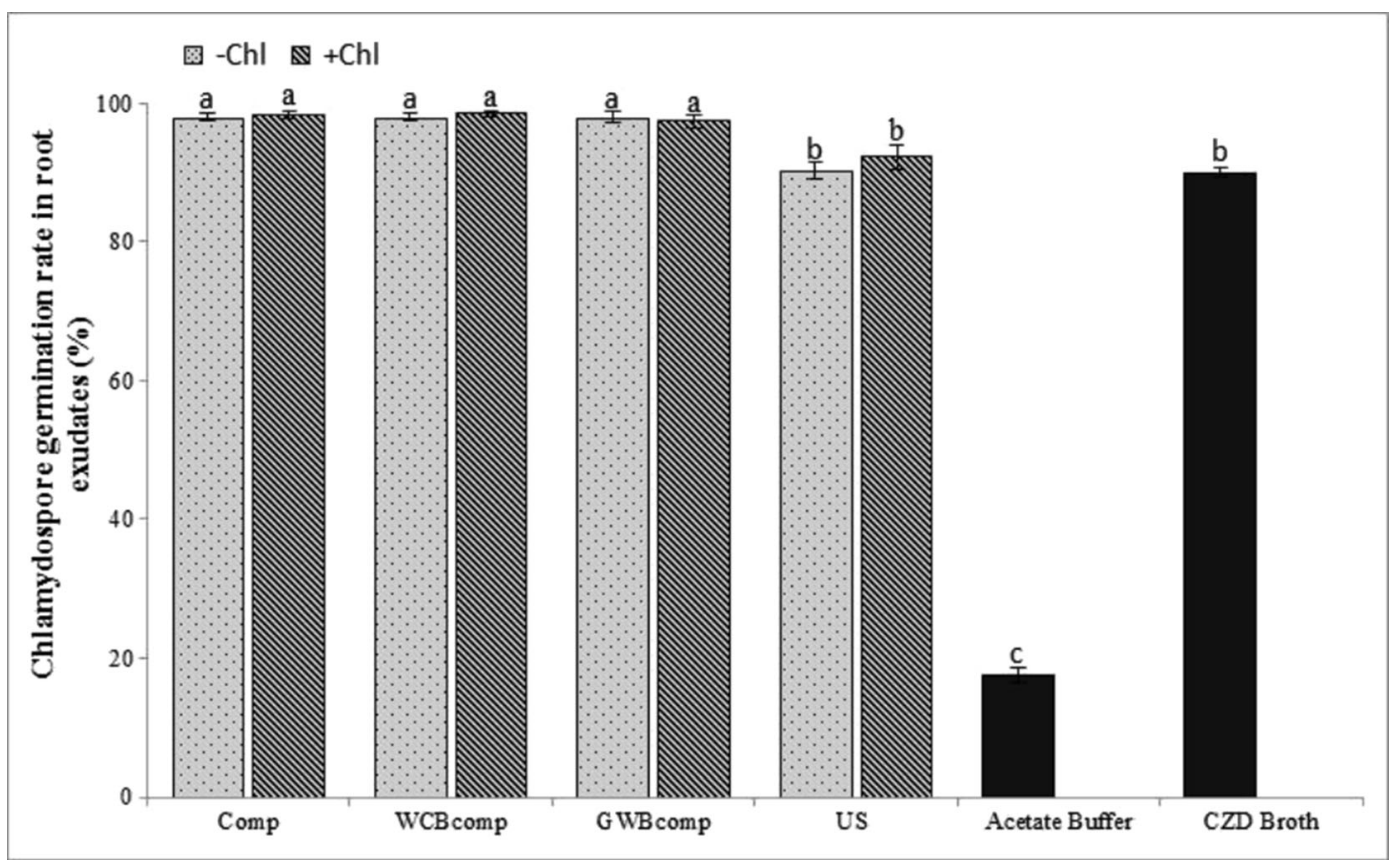

Fig 4 Chlamydospore germination rate in root exudates from tomato plants either inoculated with chlamydospores $(+\mathrm{Chl})$ or uninoculated $(-\mathrm{Chl})$ grown in different soil substrates comprising compost (Comp), compost and wood chips biochar ( $\mathrm{WCB}_{\text {comp }}$ ), compost and green waste biochar $\left(\mathrm{GWB}_{\mathrm{comp}}\right)$ or in un-amended soil
(US) after $10 \mathrm{~h}$ at $24^{\circ} \mathrm{C}$. Bars with solid filling represent chlamydospore germination rate in acetate buffer (negative control) and Czapek dox medium (Positive control; CZD). Data are mean values \pm standard error with different letters above bars that denote significant differences according to Tukey's HSD test $(P<0.05)$

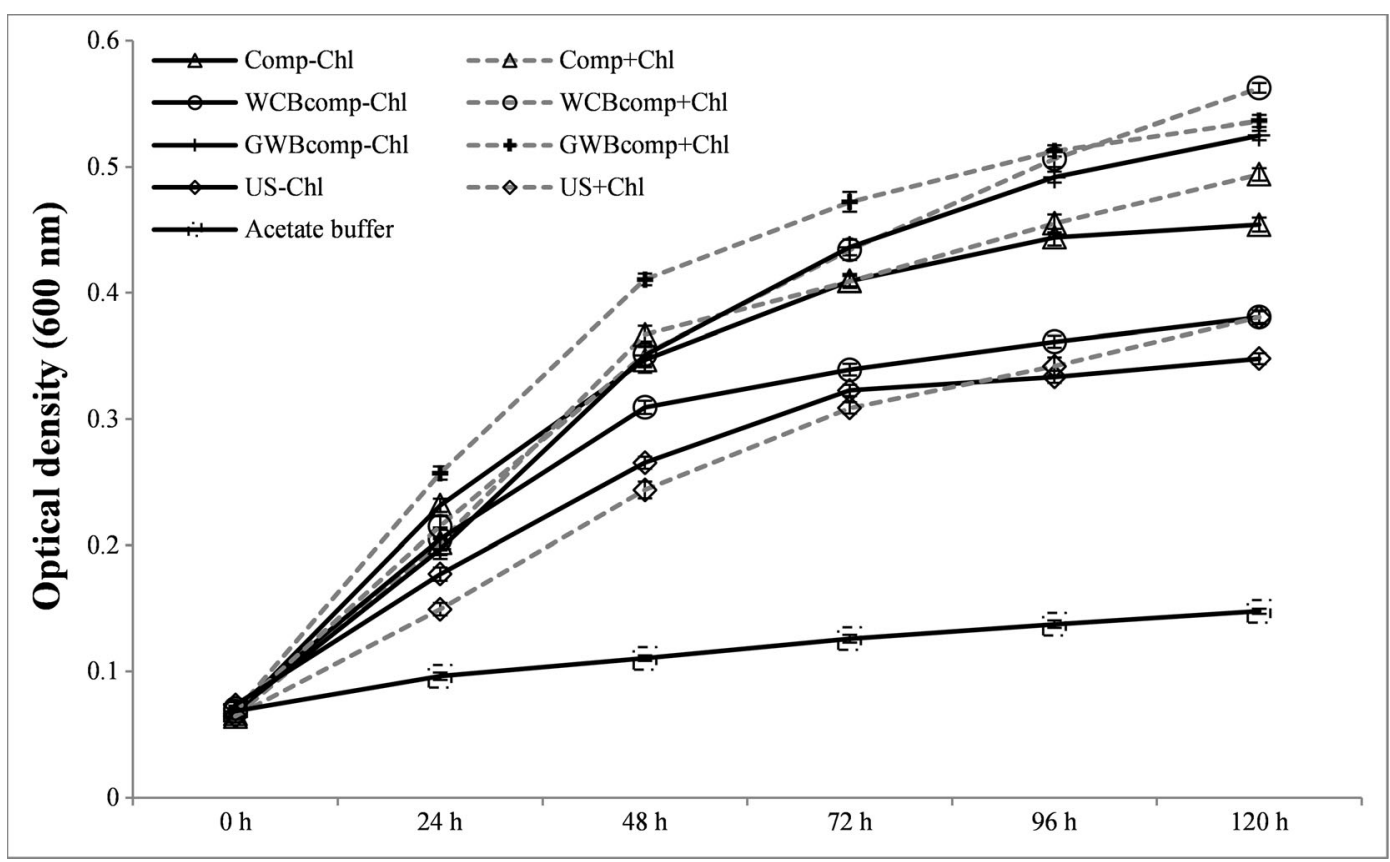

Fig 5 Differences in mycelial growth and development from chlamydospores in the root exudates of tomato plants either inoculated with chlamydospores $(+\mathrm{Chl})$ or un-inoculated $(-\mathrm{Chl})$ grown in compost (Comp), compost and wood chips biochar ( $\left.\mathrm{WCB}_{\mathrm{comp}}\right)$, compost and green waste biochar $\left(\mathrm{GWB}_{\text {comp }}\right)$ or in un-amended soil (US) monitored for a total period of five days at $24{ }^{\circ} \mathrm{C}$ after regular intervals 
We found that ' $G W B$ ' along with compost $\left(\mathrm{GWB}_{\text {comp }}\right)$ not only stimulates plant growth but also has a suppressive effect on the survival and infectivity of chlamydospores as compared to ' $\mathrm{WCB}_{\text {comp' }}$ ' and 'Comp' treatments. Previous studies have shown that an increase in soil $\mathrm{pH}$ not only suppressed the incidence of Fusarium wilt but also enhanced the tomato yield. This was because of reduced availability of nutrients such as iron and zinc to $\mathrm{Fol}$, thus, hampering its survival and development of Fusarium wilt (Jones and Woltz 1968, 1970). Similarly, higher ash contents of 'GWB' with greater ability to increase the soil $\mathrm{pH}$ (Kloss et al. 2014) plausibly contributed to enhanced plant growth and suppression of Fusarium wilt. In spite of the lower inoculum recovery from ' $\mathrm{GWB}_{\text {comp }}$ ' treatment at the plant harvesting time, the level of inoculum $\left(0.30 \times 10^{4} \mathrm{CFU} / \mathrm{g}\right.$ of dry soil) in soil is high enough to cause severe disease (Jaiswal et al. 2015; Silva-Muniz et al. 1991). The ability of inoculum to survive in the soil is reliant on the soil characteristics and organic matter contents. However, the phenomena of inoculum survival and soil suppressiveness are not necessarily linked together (Couteaudier and Alabouvette 1990; Amir and Alabouvette 1993). Elmer and Pignatello (2011) showed the reduction of $F$. oxysporum f. sp. asparagii development in asparagus without any significant effect on the pathogen survival in biochar amended potting media. In addition to that, the characteristics of the raw material used for the biochar production have a strong influence on its disease suppressing ability. Jaiswal et al. (2014, 2015) have recently reported that the biochar produced from different feedstocks had a varying effect on damping-off incidence and other disease parameters in cucumber and beans.

In order to better understand the mechanism of disease suppression, we examined the direct effect of compost and compost-biochar mixtures on the chlamydospores of Fusarium wilt. In many reports, compost associated suppressive ability to soil-borne pathogens has been eliminated after sterilisation (Larkin 2015; Yogev et al. 2006). As a consequence, poor inhibition of fungal radial growth was observed in compost amended PDA plates. Moreover, this also indicates the biotic nature of the compost associated suppression of soil-borne pathogens (Alabouvette et al. 2006; Bonanomi et al. 2007). Comparatively, a higher fungal radial growth inhibition was observed in ' $\mathrm{GWB}_{\text {comp }}$ ' treatment. A recent study also documented the in vitro ability of greenhouse waste biochar to inhibit $50 \%$ or higher radial growth of Rhizoctonia solani in comparison with eucalyptus wood biochar (Jaiswal et al. 2015). However, in the present work none of the compost and compost-biochar mixtures resulted into a fungal growth inhibition of $50 \%$ or higher. In this scenario, resistance of the plants towards infection could be the result of physical barriers or physiological changes occurring in response to biochar and compost. These alterations may have a role in avoiding the establishment of the pathogen or by confining its spread within host plant (Whalley and Taylor 1973).

The reduction in gas exchange rate and stomatal conductance has been attributed to the pathogen infection in higher plants (Wang et al. 2015). The blockage of the vascular system of plants because of Fusarium infection increases resistance to water movement which may induce symptoms similar to drought stress in plants. Therefore, stomatal conductance as well as net photosynthetic activity was reduced in tomato plants grown in chlamydospores infested soil which is in accordance with the previous studies as well (Duniway and Slatyer 1971; Nogués et al. 2002).

Our findings revealed that the plants grown in soil amended with 'GWB comp' resisted to Fusarium wiltinduced reduction to net photosynthetic activity as well as stomatal conductance in comparison to ' $\mathrm{WCB}_{\text {comp }}$ ' and 'Comp' treatments. This might be due to the increased water availability as well as to resistance of the plants to Fol colonization of xylem vessel in 'GWB comp' $^{\text {' }}$ containing soil substrate. Asai et al. (2009) and Haider et al. (2014) reported an increase in sap flow from xylem and water use efficiency in rice and maize plants, respectively, grown in biochar amended soil. Akhter et al. (2015) also suggested that the addition of biochar has positive influence on soil moisture contents which ultimately improves the growth of $\mathrm{Fol}$ microconidia inoculated tomato plants.

In our study, the combination of biochar and compost had both stimulating and suppressive effects on tomato plant growth. The plant growth was suppressed in the ' $\mathrm{WCB}_{\text {comp }}$ ' treatment whereas a positive plant growth response was observed in soil amended with

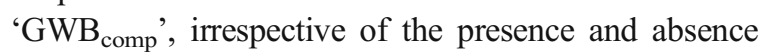
of chlamydospores. In general, the available literature documents an enhanced plant growth response under biochar application in combination with balance nutrient supply (Steiner et al. 2007; Agegnehu et al. 2015). However, there are reports suggesting negative effects of different biochar types on plant growth as well if 
biochar competes with nutrient supply for plant roots (Rajkovich et al. 2012; Chan et al. 2008). Another study showed that biochar-compost soil amendments had a non-significant effect on grapevine growth in alkaline, temperate soil (Schmidt et al. 2014). Conclusively, the response of the plants towards biochar with reference to growth stimulation and disease suppression is influenced by the type of feedstock, pyrolysis conditions, application rate of biochar, soil characteristics and nutrient availability (Akhter et al. 2015; Jaiswal et al. 2015; Graber et al. 2014).

Altered nutrient availability from biochar amended potting media can also influence the plant growth. Biochars prepared from woody feedstocks are generally lower in nutrient status and ash contents (Brewer et al. 2009; Singh et al. 2010). In contrast, biochar made from leaf-containing plant materials are richer in readily available nutrients to plants (Mukherjee and Zimmerman 2013). Besides, the phenomenon of 'hormesis' where biochar borne small quantities of toxic elicitor compounds such as phenolics and organic acids stimulating plant growth should also be considered (Graber et al. 2014). In addition to biochar, the response of the plants may also vary with the host, pathogen type and inoculum source. However, it is hard to determine a single factor responsible for the possible effects of biochar on plant growth and pathogen impact because of the interactions between them.

Root architecture is not only influenced by the genetics but also by the environmental conditions (i.e. organic amendments of the soil, bulk density, nutrient and water availability) have their role in modulating of root development and exudation (Caffaro et al. 2011; Hodge 2004). We observed a slight impact on tomato plants root length grown in chlamydospore infested biochar and compost amended soil. It appears that the incorporation of compost in the soil substrate has an inhibitory effect on $\mathrm{Fol}$ induced changes in the root morphology. Recently, Morauf and Steinkellner (2015) have also shown the stabilizing effect of compost against the $\mathrm{Fol}$ induced changes in tomato root traits. Soil additives not only effect root morphology but also have a strong influence on quality and composition of root exudates. Substrate dependent root exudation has previously been described in Lupinus albus and Brassica napus (Mimmo et al. 2011) and in tomato plants (Akhter et al. 2015). Recently Neumann et al. (2014) has also shown the strong influence of different soil types on the root exudates of Lactuca sativa. Principally, root exudates play an important role in the establishment of diseases caused by soil-borne pathogenic fungi (Haichar et al. 2014). However, little is known about the interaction between root exudates and wilt-inducing Fusarium chlamydospores.

To test the direct effect of tomato root exudates obtained from plants grown in different soil substrate compositions on the chlamydospores germination and mycelial growth, chlamydospores were directly added to the extracted root exudates. Interestingly, a very high germination rate of chlamydospores was observed in the root exudates from all the treatments, unlike to the diverse pattern of microconidia germination. This observation correlates with the findings of Schippers and Voetberg (1969) that no specific activating or suppressing substances were released by the roots of susceptible and resistant pea cultivars which could influence $F$. oxysporum f. sp. pisi chlamydospore germination. Moreover, the higher germination rate of chlamydospores was associated with the root exudates containing ninhydrin positive substances and reducing sugars. Whalley and Taylor (1973) also noticed higher germination rates of chlamydospores of $F$. oxysporum and $F$. solani $\mathrm{f}$. sp. pisi incubated in root exudates under sterile conditions irrespective to the origin of the exudates. However, microconidia germination is vulnerable to alterations in response to the lower concentrations of chlorogenic acid and citrate in root exudates (HageAhmed et al. 2013). In our previous study (Akhter et al. 2015), we also found variations in the $\mathrm{Fol}$ microconidia germination responsiveness to the root exudates of plants grown in biochar and compost amended soil. The reduction in microconidia germination rate was shown in tomato plant root exudates taken from 50 to 60 days old plants because plant age induced alterations in sugars and organic acid contents of the root exudates (Steinkellner et al. 2005). In contrast, our study shows higher microconidia germination rate in compost and biochar amended treatments indicating substrate-induced qualitative or quantitative changes in the root exudates.

Contrary to the uniform chlamydospore germination response, the differences in mycelial growth and development became prominent when chlamydospores were exposed to the root exudates for longer period of time. We found that the root exudates influence mycelial growth and development differently to microconidia or chlamydospore germination. Mycelial growth was augmented in root exudates from inoculated $(+\mathrm{Chl})$ plants 
grown in ' $\mathrm{WCB}_{\mathrm{comp}}$ ' treatments and interestingly lowest mycelial growth was also in the exudates from plants

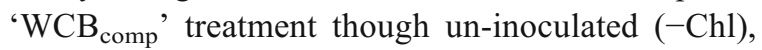
along with 'US' treatment. On the other hand, nonsignificant differences were observed in mycelial growth in exudates from plants grown in ' $\mathrm{GWB}_{\text {comp }}$ ' treatment either inoculated or un-inoculated. Together with biochar and compost tomato roots upon infection with $F$. oxysporum influenced the composition of root exudates probably because of exudation of new compounds or by altering the composition of root exudates (Akhter et al. 2015; Steinkellner et al. 2008; Benhamou 1991). The level of sugar contents and secondary metabolites such as flavonoids in the root exudates varies during tomato- $\mathrm{Fol}$ interaction which ultimately plays a role in stimulating or supressing the mycelial growth and development (Hage-Ahmed et al. 2013; Steinkellner and Mammerler 2007). However, the extent of alteration of root exudates induced by Fol might also depend upon severity of infection.

The different inoculum sources of $\mathrm{Fol}$ react in a specific way to the root exudates indicating the responsiveness of fungal microconidia, chlamydospore and mycelial growth to different fractions of the root exudates. Additional studies are required to better understand the mechanism involved in alterations of the exudates in response to soil organic amendments and pathogen infection. Disease severity in the field is not only influenced by root exudate mediated chlamydospore germination or mycelial growth (Smith 1977). The fate of plants either being resistant or susceptible to pathogenic Fusarium might be decided on or within the roots (Steinberg et al. 1999). Thus, soil substrate induced changes in plant physiology and microbial behaviour have to be considered (Akhter et al. 2015; Amir and Alabouvette 1993).

To summarize, our study demonstrates an enhanced plant growth and suppression of wilt-inducing chlamydospores in green waste biochar amended soil. The combined application of biochar produced from different feedstocks and compost has a variable effect on the infectivity potential of chlamydospores. The influence of the two different biochars on plant performance and Fusarium-wilt suppression is dependent on the physical and chemical properties of the biochar. The present study, to our knowledge is the first to highlight the great potential of green waste biochar and compost combination as a soil organic amendment in positively stimulating tomato plant growth and suppressing the disease causing ability of Fusarium wilt-inducing chlamydospores. Apart from the direct or indirect effects of the biochar on the nutrient availability and $\mathrm{Fol}$, alternative mechanisms encompassing biochar-borne chemicals together with shift in soil associated microbial communities plausibly contributed to elicit plant growth and defense response. There is a great scope of biochar in disease management programs; however, further work is needed to elucidate the mechanisms involved and to evaluate the plant protection potential of biochars.

Acknowledgments Open access funding provided by University of Natural Resources and Life Sciences Vienna (BOKU). Adnan Akhter gratefully acknowledges the Higher Education Commission (HEC) of Pakistan for financial support. We are thankful to Karin Baumgartner for technical assistance.

Open Access This article is distributed under the terms of the Creative Commons Attribution 4.0 International License (http:// creativecommons.org/licenses/by/4.0/), which permits unrestricted use, distribution, and reproduction in any medium, provided you give appropriate credit to the original author(s) and the source, provide a link to the Creative Commons license, and indicate if changes were made.

\section{References}

Agegnehu G, Bass AM, Nelson PN, Muirhead B, Wright G, Bird MI (2015) Biochar and biochar-compost as soil amendments: effects on peanut yield, soil properties and greenhouse gas emissions in tropical North Queensland, Australia. Agric Ecosyst Environ 213:72-85

Agrios GN (2005) Plant pathology. Elsevier-Academic Press, San Diego

Akhter A, Hage-Ahmed K, Soja G, Steinkellner S (2015) Compost and biochar alter mycorrhization, tomato root exudation, and development of Fusarium oxysporum $\mathrm{f}$. sp. lycopersici. Front Plant Sci 6: 529. doi:10.3389/fpls.2015.00529

Alabouvette C, Olivain C, Steinberg C (2006) Biological control of plant diseases: the European situation. Eur J Plant Pathol 114:329-341

Amir H, Alabouvette C (1993) Involvement of soil abiotic factors in the mechanisms of soil suppressiveness to fusarium wilts. Soil Biol Biochem 25:157-164

Asai H, Samson B, Stephan H, Songyikhangsuthor K, Homma K, Kiyono Y, Inoue Y, Shiraiwa T, Horie T (2009) Biochar amendment techniques for upland rice production in northern Laos. Soil physical properties, leaf SPAD and grain yield. Field Crop Res 111:81-84

Beckman CH (1987) The nature of wilt diseases of plants. The American Phytopathological Society Press, St. Paul

Benhamou N, Grenier J, Chrispeels MJ (1991) Accumulation of beta-fructosidase in the cell walls of tomato roots following 
infection by a fungal wilt pathogen. Plant Physiol 97:739750

Bennett R, Davis RM (2013) Method for rapid production of Fusarium oxysporum f. sp. vasinfectum chlamydospores. J Cotton Sci 17:52-59

Bonanomi G, Antignani V, Pane C, Scala F (2007) Suppression of soilborne fungal diseases with organic amendments. J Plant Pathol 89:311-324

Brewer CE, Schmidt-Rohr K, Satrio JA, Brown RC (2009) Characterization of biochar from fast pyrolysis and gasification systems. Environ Prog Sustain Energy 28:386-396

Caffaro MM, Vivanco JM, Gutierrez Boem FH, Rubio G (2011) The effect of root exudates on root architecture in Arabidopsis thaliana. Plant Growth Regul 64:241-249

Chan KY, Van Zwieten L, Meszaros I, Downie A, Joseph S (2008) Using poultry litter biochars as soil amendments. Aust J Soil Res 46:437-444

Couteaudier Y, Alabouvette C (1990) Survival and inoculum potential of conidia and chlamydospores of Fusarium oxysporum f. sp. lini in soil. Can J Microbiol 36:551-556

Dean R, van Kan JAL, Pretorius ZA, Hammond-Kosack KE, Di Pietro A, Spanu PD, Rudd JJ, Dickman M, Kahmann R, Ellis J, Foster GD (2012) The top 10 fungal pathogens in molecular plant pathology. Mol Plant Pathol 13:414-430

De-Cal A, Pascual S, Melgarejo P (1997) Infectivity of chlamydospores vs microconidia of Fusarium oxysporum f. sp. lycopersici on tomato. J Phytopathol 145:231-233

Duniway JM, Slatyer RO (1971) Gas exchange studies on the transpiration and photosynthesis of tomato leaves affected by Fusarium oxysporum f. sp. lycopersici. Phytopathology 61: 1377-1381

Elad Y, David DR, Meller Harel Y, Borenshtein M, Ben Kalifa H, Silber A, Graber ER (2010) Induction of systemic resistance in plants by biochar, a soil-applied carbon sequestering agent. Phytopathology 100:913-921

Elmer WH, Pignatello JJ (2011) Effect of biochar amendments on mycorrhizal associations and fusarium crown and root rot of asparagus in replant soils. Plant Dis 95:960-966

FAOSTAT (2015) Food and Agriculture Organization of the United Nations http://faostat3.fao.org/download/Q/QC/E. Accessed 28 January 2016

Fischer D, Glaser B (2012) Synergisms between compost and biochar for sustainable soil amelioration. In: Sunil K, Bharti A (eds) Management of organic waste. InTech, Rijeka, Croatia, pp. 167-198

Fravel D, Olivain C, Alabouvette C (2003) Fusarium oxysporum and its biocontrol. New Phytol 157:493-502

Goyal JP, Maraite H, Meyer JA (1973) Abundant production of chlamydospores by Fusarium oxysporum f. sp. melonis in soil extract with glucose. Neth J Plant Pathol 79:162-164

Graber ER, Frenkel O, Jaiswal AK, Elad Y (2014) How may biochar influence severity of diseases caused by soilborne pathogens? Carbon Manag 5:169-183

Hage-Ahmed K, Moyses A, Voglgruber A, Hadacek F, Steinkellner S (2013) Alterations in root exudation of intercropped tomato mediated by the arbuscular mycorrhizal fungus Glomus mosseae and the soil borne pathogen Fusarium oxysporum f. sp. lycopersici. J Phytopathol 161:763-773

Haichar FZ, Santaella C, Heulin T, Achouak W (2014) Root exudates mediated interactions belowground. Soil Biol Biochem 77:69-80
Haider G, Koyro H-W, Azam F, Steffens D, Müller C, Kammann C (2014) Biochar but not humic acid product amendment affected maize yields via improving plant-soil moisture relations. Plant Soil 395:141-157

Harel MY, Elad Y, Rav-David D, BorensteinM SR, Lew B, Graber ER (2012) Biochar mediates systemic response of strawberry to foliar fungal pathogens. Plant Soil 357:245-257

Hodge A (2004) The plastic plant: root responses to heterogeneous supplies of nutrients. New Phytol 162:9-24

Jaiswal AK, Elad Y, Graber ER, Frenkel O (2014) Rhizoctonia solani suppression and plant growth promotion in cucumber as affected by biochar pyrolysis temperature, feedstock and concentration. Soil Biol Biochem 69:110-118

Jaiswal AK, Frenkel O, Elad Y, Lew B, Graber ER (2015) Nonmonotonic influence of biochar dose on bean seedling growth and susceptibility to Rhizoctonia solani: the "shifted Rmax -effect”. Plant Soil 395:125-140

Jones JP, Woltz SS (1968) Field control of fusarium wilt (race 2) of tomato by liming and stake disinfestation. Proc Fla State Hortic Soc 81:167-191

Jones JP, Woltz SS (1970) Fusarium wilt of tomato: interaction of soil liming and micronutrient amendments on disease development. Phytopathology 60:812-813

Kammann CI, Schmidt HP, Messerschmidt N, Linsel S, Steffens D, Müller C, et al. (2015) Plant growth improvement mediated by nitrate capture in co-composted biochar. Sci Rep 5: 11080. doi:10.1038/srep11080

Kloss S, Zehetner F, Wimmer B, Buecker J, Rempt F, Soja G (2014) Biochar application to temperate soils: effects on soil fertility and crop growth under greenhouse conditions. J Plant Nutr Soil Sci 177:3-15

Kommedahl T (1966) Relation of exudates of pea roots to germination of spores in races of Fusarium oxysporum f. pisi. Phytopathology 56:721-722

Larkin RP (2015) Soil health paradigms and implications for disease management. Annu Rev Phytopathol 53:10.1-10.23

Massee G (1895) The "sleepy disease" of tomatoes. Gard Chron 3: $705-707$

McGovern RJ (2015) Management of tomato diseases caused by Fusarium oxysporum. Crop Prot 73:78-92

Mehta CM, Palni U, Franke-Whittle IH, Sharma AK (2014) Compost: its role, mechanism and impact on reducing soilborne plant diseases. Waste Manag 34:607-622

Mimmo T, Hann S, Jaitz L, Cesco S, Gessa CE, Puschenreiter M (2011) Time and substrate dependent exudation of carboxylates by Lupinus albus L. And Brassica napus L. Plant Physiol Biochem 49:1272-1278

Morauf C, Steinkellner S (2015) Fusarium oxysporum f. sp. lycopersici and compost affect tomato root morphology. Eur J Plant Pathol 143:385-398

Mukherjee A, Lal R (2014) The biochar dilemma. Soil Res 52: 217-230

Mukherjee A, Zimmerman AR (2013) Organic carbon and nutrient release from a range of laboratory-produced biochars and biochar-soil mixtures. Geoderma 193:122-130

Nash SM, Snyder WC (1962) Quantitative estimations by plate counts of propagules of the bean root rot fusarium in field soils. Phytopathology 52:567-572

Neumann G, Bott S, Ohler MA, Mock H-P, Lippmann R, Grosch R, Smalla K (2014) Root exudation and root development of 
lettuce (Lactuca sativa L. cv. Tizian) as affected by different soils. Front Microbiol 5:2. doi:10.3389/fmicb.2014.00002

Nogués S, Cotxarrera L, Alegre L, Trillas MI (2002) Limitations to photosynthesis in tomato leaves induced by fusarium wilt. New Phytol 154:461-470

Rajkovich S, Enders A, Hanley K, Hyland C, Zimmerman AR, Lehmann J (2012) Corn growth and nitrogen nutrition after additions of biochars with varying properties to a temperate soil. Biol Fertil Soils 48:271-284

Ruano-Rosa D, Mercado-Blanco J (2015) Combining biocontrol agents and organics amendments to manage soil-borne phytopathogens. In: Meghvansi MK, Varma A (eds) Organic amendments and soil suppressiveness in plant disease management. Springer International Publishing, Switzerland, pp. $457-478$

Rush CM, Kraft JM (1986) Effects of inoculum density and placement on fusarium root rot of peas. Phytopathology 76: $1325-1329$

Schippers B, Voetberg JS (1969) Germination of chlamydospores of Fusarium oxysporum f. sp. pisi race 1 in the rhizosphere, and penetration of the pathogen into roots of a susceptible and a resistant pea cultivar. Neth J Plant Pathol 75:241-258

Schmidt HP, Kammann C, Niggli C, Evangelou MWH, Mackie KA, Abiven S (2014) Biochar and biochar-compost as soil amendments to a vineyard soil: influences on plant growth, nutrient uptake, plant health and grape quality. Agric Ecosyst Environ 191:117-123

Silva-Muniz MF, Muchovej JJ, Maffia LA, Muchovej RMC, Brommonschenkel SH, Alvarez-Venegas VH (1991) Influence of calcium nutrition on wilt of dry bean. Pesq Agrop Brasileira 26:2033-2041

Singh B, Singh BP, Cowie AL (2010) Characterisation and evaluation of biochars for their application as a soil amendment. Aust J Soil Res 48:516-525

Smith SN (1977) Comparison of germination of pathogenic Fusarium oxysporum chlamydospores in host rhizosphere soils conducive and suppressive to wilts. Phytopathology 67:502-510

Smith SN (2007) An overview of ecological and habitat aspects in the genus Fusarium with special emphasis on the soil-borne pathogenic forms. Plant Pathol Bull 16:97-120

Smith JL, Collins HP (2007) Management of organisms and their processes in soils. In: Paul EA (ed) Soil microbiology ecology and biochemistry, 3rd edn. Academic Press, Burlington, pp. 471-502

Smith SN, Snyder WC (1972) Germination of Fusarium oxysporum chlamydospores in soils favourable and unfavourable to wilt establishment. Phytopathology 62: 273-277

Sohi S, Krull E, Lopez-Capel E, Bol R (2010) A review of biochar and its use and function in soil. Adv Agron 105:47-82

Steinberg C, Whipps JM, Wood D, Fenlon J, Alabouvette C (1999) Mycelial development of Fusarium oxysporum in the vicinity of tomato roots. Mycol Res 103:769-778

Steiner C, Teixeira WG, Lehmann J, Nehls T, de Macedo JLV, Blum WEH, Zech W (2007) Long term effects of manure, charcoal and mineral fertilization on crop production and fertility on a highly weathered central Amazonian upland soil. Plant Soil 291:275-290

Steinkellner S, Langer I (2004) Impact of tillage on the incidence of Fusarium spp. in soil. Plant Soil 267:13-22

Steinkellner S, Mammerler R (2007) Effect of flavonoids on the development of Fusarium oxysporum f. sp. lycopersici. J Plant Interact 2:17-23

Steinkellner S, Mammarler R, Vierheilig H (2005) Microconidia germination of tomato pathogen Fusarium oxysporum in the presence of root exudates. J Plant Interact 1:23-30

Steinkellner S, Mammerler R, Vierheilig H (2008) Germination of Fusarium oxysporum strains in root exudates from tomato plants challenged with different Fusarium oxysporum strains. Eur J Plant Pathol 122:395-401

Takken F, Rep M (2010) The arms race between tomato and Fusarium oxysporum. Mol Plant Pathol 11:309-314

Wang M, Sun Y, Sun G, Liu X, Zhai L, Shen Q, Guo S (2015) Water balance altered in cucumber plants infected with Fusarium oxysporum f. sp. cucumerinum. Sci Rep 5:7722. doi:10.1038/srep07722

Whalley WM, Taylor GS (1973) Influence of pea-root exudates on germination of conidia and chlamydospores of physiologic races of Fusarium oxysporum f. pisi. Ann Appl Biol 73:269276

Yogev A, Raviv M, Hadar Y, Cohen R, Katan J (2006) Plant waste-based composts suppressive to diseases caused by pathogenic Fusarium oxysporum. Eur J Plant Pathol 116: 267-278 